\title{
Experimentos de baixo custo aplicados ao ensino de química: contribuição ao processo ensino-aprendizagem.
}

Low cost experiments applied to the teaching of chemistry: contribution to teaching learning process.

\author{
J. N. da Silva ${ }^{1}$; J.S. Amorim ${ }^{1}$; L. P. Monteiro ${ }^{1}$; K.H. G. Freitas ${ }^{2 *}$ \\ ${ }^{1}$ (Graduada de Licenciatura em Química, Faculdade de Química, UNIFESSPA); \\ ${ }^{2}$ Faculdade de Engenharia de Materiais - Campus Ananindeua-Universidade Federal do Pará, 66075-900 \\ Ananindeua PA-Brasil. \\ *heloizy@ufpa.br
}

(Recebido em 10 de agosto de 2016; aceito em 31 de agosto de 2016)

\begin{abstract}
Resumo: Este artigo relata uma proposta metodológica baseada na perspectiva construtivista aplicada ao ensino público na cidade de Marabá-PA. Este teve como objetivo investigar a contribuição da utilização de atividades experimentais no ensino de química em escolas públicas de ensino médio de forma simples com materiais de baixo custo, sendo abordados dois temas: Cinética Química e Eletroquímica. Em cinética química, foi objetivo compreender os conceitos e analisar a importância da velocidade das reações químicas, assim como verificar quais são os fatores que aceleram, reduzem ou que proporcionam as condições necessárias para que as reações possam ocorrer. Em eletroquímica o objetivo principal foi compreender as reações de óxido-redução que representam um conjunto de fenômenos comumente observados no dia-a-dia, o que possibilita uma abordagem contextualizada na qual os conceitos físicoquímicos estão envolvidos. Este trabalho, portanto, almeja proporcionar ao professor de ensino médio (professores de química), a possibilidade de aulas mais ilustrativas e experimentais, de maneira simples e prática, além de ratificar a importância de aulas experimentais no ensino de química para alunos da rede pública.

Palavras-chave: Experimentos de baixo custo, Ensino de química, Materiais alternativos
\end{abstract}

Abstract: This paper describes a methodology based on the constructivist perspective of public education in the city of Marabá, Brazil, which the objective was to investigate and contribute to the use of experimental activities simply and with low cost materials to learning of chemistry for high school, being approached two themes: Chemical Kinetics and Electrochemistry. In chemical kinetics, was objective to understand strategies and analyze the importance of the rate of chemical reactions, as well as checking what are the factors that accelerate, decrease or provide the necessary conditions for the reactions may occur. In electrochemical, understand the oxidation-reduction reactions that represent a set of phenomena commonly observed in day-to-day was objective, which allows a contextualized approach in which the physical and chemical concepts are involved. This paper therefore aims to provide a high school teacher (chemistry teachers), the possibility of a more illustrative and test lesson in a simple and practical way. Keywords: Low cost experiments, teaching of Chemistry, Alternative Materials

\section{INTRODUÇÃO}

A abordagem experimental na sala de aula está intimamente ligada à função pedagógica de auxiliar o aluno a explicitação, problematização, discussão, ou seja, na significação dos conceitos químicos. O experimento deve ser parte do contexto de sala de aula e seu encaminhamento não pode separar a teoria da prática, num processo pedagógico em que os alunos se relacionem com os fenômenos vinculados aos conceitos químicos a serem formados e significados na aula [1]. 
Segundo Valadares (2000) [2] "Um dos maiores desafios do ensino de Química, nas escolas de nível médio, é construir uma ponte entre o conhecimento escolar e o cotidiano dos alunos. Frequentemente, a ausência deste vínculo é responsável pela apatia e distanciamento entre alunos e professores".

As atividades experimentais, utilizando ou não o ambiente de laboratório escolar convencional, podem ser o ponto de partida para a compreensão de conceitos e sua relação com as ideias a serem discutidas em sala de aula. Os estudantes, assim, estabelecem relações entre a teoria e a prática e, ao mesmo tempo, expressam ao professor suas dúvidas. Uma aula experimental, seja ela com manipulação do material pelo aluno ou demonstrativa, não precisa e nem deve estar ligada à instrumentos caros e sofisticados, mas sim, à sua organização, discussão e análise, possibilitando interpretar os fenômenos químicos e a troca de informações entre o grupo que participa da aula [3].

No caso do ensino da química, essa prática é de extrema importância já que seus conceitos estão facilmente encontrados em nosso cotidiano. Por isso, se a criança se familiariza com as ciências desde cedo, mais chances terá de se desenvolver em qualquer campo [4].

Lima et al. (2000) [5], considera que as atividades didáticas, muitas vezes, são baseadas em aulas expositivas, que não levam em conta nem os conhecimentos prévios nem o cotidiano dos alunos. Especificamente o ensino de cinética química, ramo da química que estuda a velocidade das reações e os fatores que a influenciam, por se tratar de um tema bastante abstrato para os alunos, a experimentação pode ser um instrumento que irá facilitar o ensino-aprendizagem do conteúdo.

De acordo com MINISTÉRIO DA EDUCAÇÃO [6] "a formação do aluno deve ter como alvo principal a aquisição de conhecimentos básicos, a preparação científica e a capacidade de utilizar as diferentes tecnologias relativas às áreas de atuação".

Assumpção et al. (2011) [7] adaptaram materiais alternativos de baixo custo para experimentos de titulação ácido base em substituição aos materiais usuais como bureta, balão volumétrico, entre outros. A viabilidade do emprego desse material alternativo foi demonstrada na padronização de uma solução de soda cáustica utilizando ácido acetilsalicílico como padrão primário.

A eletroquímica, entre outras palavras, a conversão de energia química em energia elétrica é um fenômeno que pode e deve ser explorado exaustivamente pelos professores do ensino médio, em virtude de ilustrar vários conceitos químicos e físicos que, embora façam parte da rotina diária de qualquer pessoa, nem sempre são evidentes aos estudantes, criando-se uma indesejável separação entre conceitos e experiência. As pilhas sugeridas em livros didáticos do ensino médio sejam aquelas com materiais típicos de laboratório, como por exemplo, a pilha de Daniell, sejam as menos clássicas, como pilhas à base de limão e/ou batata devem ser usadas como instrumento de aprendizagem em aulas de química.

Assim, cria-se a necessidade de utilizar formas alternativas de ensino sempre tentando despertar o interesse, o raciocínio e o entendimento dos conceitos químicos. Uma forma de viabilizar os experimentos nas escolas de ensino médio é a adaptação de equipamentos e materiais alternativos que podem ser construídos com utensílios do cotidiano.

Neste trabalho descreveremos experimentos relacionados á dois temas de química ministrados no ensino médio, cinética química e eletroquímica, que foram realizados com alunos da rede pública com objetivo de contribuir para o binômio ensino-aprendizagem. Estes experimentos são de fácil execução e utiliza materiais alternativos e de baixo custo. Também ratificamos a importância de aulas experimentais no ensino de química por meio de questionários pedagógicos de aprendizagem. 


\section{MATERIAL E MÉTODOS}

\subsection{Metodologia}

A proposta das aulas práticas empregadas consistiu-se na seleção de material de baixo custo que poderiam ser utilizados na realização de experimentos de química relacionados aos temas: Cinética Química e Eletroquímica. Estes experimentos foram realizados na Escola Estadual de Ensino Médio Dr. Gaspar Viana, localizada na Cidade de Marabá - PA.

Primeiramente foi realizada a visita à escola e após apresentação do escopo do trabalho a direção e aos docentes da escola elaboramos dois questionários que deveriam ser aplicados aos alunos. Um sobre os temas abordados e outro pedagógico com objetivo de identificar as dificuldades de aprendizagem em química desses alunos.

As atividades foram desenvolvidas com a participação de turmas do segundo e terceiro ano do ensino médio, turmas essas pré-estabelecidas pelos docentes de Química da escola.

Estes questionários objetivaram coletar dados para análise estatística como forma de avaliar a importância de aulas experimentais no ensino de química para alunos do nível médio de escolas públicas.

\section{2 - Material utilizado}

A proposta de aula prática empregada consistiu na seleção de material de baixo custo. Para a construção do material didático utilizou-se os seguintes itens: Recipiente plástico, água oxigenada comercial volume 10 e 20 , detergente líquido, batata, solução de iodeto encontrado em farmácia local, seringa de 5 e $10 \mathrm{ml}$, conta gotas, ralador de verduras comum, moeda de cobre, fio de cobre, prego, calculadora, água sanitária, esponja de aço, lâmpada, bocal de caneta, sal de cozinha e colher descartável.

\section{3 - Aplicação do projeto}

Primeiramente foram aplicados questionários pedagógico e didático, antes do professor abordar os temas em sala de aula, após as aulas teóricas e após as aulas práticas para que fosse possível comparar a evolução de aprendizado entre alunos que assistiram às aulas teóricas e fizeram os experimentos e os que somente assistiram às aulas teóricas.

Na Tabela 1 é mostrado o questionário pedagógico que foi aplicado e na Tabela 2, são apresentados alguns dos questionamentos feitos sobre os temas cinética química e eletroquímica. Todas as respostas do questionário foram de múltipla escolha.

A partir dos dados coletados com os questionários, foi possível avaliar o embasamento teórico que os alunos precisavam para dar continuidade ao desenvolvimento do trabalho, foi realizado um tratamento estatístico para avaliar os resultados obtidos.

Também foi elaborado um material didático com vários temas de química abordados e entregues para os professores da escola pública alvo do estudo, esse material didático teve como objetivo capacitar os professores do ensino médio da rede pública a realizarem experimentos de baixo custo e de fácil elaboração para melhor ilustrar os conteúdos de química nas aulas. 
Tabela 1- Questionário pedagógico aplicado aos alunos do ensino médio de escola publica

\begin{tabular}{|c|c|}
\hline Perguntas & Respostas \\
\hline $\begin{array}{l}\text { A respeito de sua atenção } \\
\text { em sala de aula? }\end{array}$ & $\begin{array}{l}\text { a) Tenho } 100 \% \text { de atenção. } \\
\text { b) Tenho mais que } 80 \% \text { de atenção. } \\
\text { c) Tenho entre } 50 \text { e } 70 \% \text { de atenção. } \\
\text { d) Minha atenção é menor que } 50 \% \text {. } \\
\text { e) Não tenho atenção nenhuma. }\end{array}$ \\
\hline $\begin{array}{l}\text { A respeito do conteúdo de } \\
\text { química ministrado em sala } \\
\text { de aula? }\end{array}$ & $\begin{array}{l}\text { a) Ótimo, muito interessante. } \\
\text { b) Bom, mas poderia ser melhor. } \\
\text { c) Razoável, poderia ser melhor. } \\
\text { d) Chato, o conteúdo me dá sono. }\end{array}$ \\
\hline $\begin{array}{l}\text { A respeito do aprendizado } \\
\text { em sala de aula? }\end{array}$ & $\begin{array}{l}\text { a) Entendo tudo. } \\
\text { b) Entendo, mas tenho dificuldade com alguns conceitos. } \\
\text { c) Entendo metade do conteúdo, e me esforço para entender tudo. } \\
\text { d) Entendo metade do conteúdo e não quero saber do resto. } \\
\text { e) Não entendo nada }\end{array}$ \\
\hline $\begin{array}{l}\text { O que poderia tornar sua } \\
\text { aula de química mais } \\
\text { interessante? }\end{array}$ & $\begin{array}{l}\text { a) A professora repetir a explicação pelo menos } 4 \text { vezes. } \\
\text { b) A professora passar mais exercício de química. } \\
\text { c) Realizar experimentos de química em sala de aula. } \\
\text { d) A professora passar avaliação surpresa. } \\
\text { e) Nada }\end{array}$ \\
\hline $\begin{array}{l}\text { Qual o seu interesse em } \\
\text { química? }\end{array}$ & $\begin{array}{l}\text { a) Alto, pretendo ser um Químico. } \\
\text { b) Médio, pretendo apenas passar na disciplina. } \\
\text { c) Baixo, odeio química }\end{array}$ \\
\hline
\end{tabular}

Tabela 2- Algumas perguntas feitas aos alunos no questionário didático.

\section{Cinética Química}

\begin{tabular}{ll}
\hline 1 & Cinética e o ramo da química que estuda? \\
\hline 2 & Qual a função de um catalisador? \\
\hline 3 & Em qual dos recipientes a reação ocorreu com maior velocidade? \\
\hline Eletroquímica & \\
\hline 2 & O eletrodo que sofre oxidação recebe o nome de? \\
\hline 3 & Qual o fato que fez a lâmpada no experimento acender? \\
\hline
\end{tabular}

Fonte: Autores do trabalho

\section{4 -Experimentos de química em sala de aula}

\subsection{1- Cinética Química}

Nos experimentos de química com o tema cinética química foi utilizada a reação de decomposição do peróxido de hidrogênio, também conhecida como água oxigenada. Está reação é de fácil visualização por haver liberação de gás com formação de bolhas, de acordo com a equação 1.

$$
\mathrm{H}_{2} \mathrm{O}_{2(\mathrm{l})} \rightarrow \mathrm{H}_{2} \mathrm{O}_{(\mathrm{l})}+1 / 2 \mathrm{O}_{2(\mathrm{~g})} \quad \text { equação } 1
$$

\section{a) Temperatura e a velocidades das reações.}

Foi colocado $5 \mathrm{ml}$ de água oxigenada volume 10 em três recipientes plásticos umedecidos com detergente líquido, um foi esfriado à $15^{\circ} \mathrm{C}$, o segundo, estava em temperatura ambiente e o terceiro foi aquecido à $40^{\circ} \mathrm{C}$ (em banho Maria). Adicionou-se 2 gotas de iodeto de sódio nos três recipientes plásticos. 
Neste experimento, os alunos do ensino médio da rede pública foram capazes de verificar a influência da temperatura na velocidade de reação. Com o aumento da temperatura a velocidade da reação aumenta, dessa forma foi visualizado que a $40^{\circ} \mathrm{C}$ a velocidade da reação foi maior do que a temperatura ambiente. $\mathrm{E}$ a $15^{\circ} \mathrm{C}$ (menor temperatura) a reação de decomposição da água oxigenada foi mais baixa, ou seja, gatou mais tempo para acontecer.

\section{b) Influência da concentração dos reagentes sobre a velocidade das reações.}

Foi adicionado $5 \mathrm{ml}$ de água oxigenada comercial vol. $10 \mathrm{em}$ um recipiente plástico e $5 \mathrm{ml}$ de água oxigenada comercial vol. 20 no outro recipiente plástico, previamente umedecido com detergente líquido. Adicionou-se 2 gotas de solução de iodeto de sódio nos dois recipientes plásticos.

Quanto maior a concentração do reagente maior será velocidade da reação. Esta teoria foi visualizada pelos estudantes quando a reação no recipiente que continha água oxigenada vol. 20 acabou na metade do tempo da reação do recipiente que continha vol. 10.

\section{c) Área de contato e a velocidade das reações.}

Colocou-se $5 \mathrm{ml}$ de água oxigenada comercial vol. 10 nos três recipientes plásticos, já umedecidos com detergente, adicionou-se a mesma quantidade de batata nos recipientes plásticos, no primeiro colocou-se um pedaço grande de batata, no segundo recipiente a batata em tiras e no terceiro adicionou-se a batata ralada simultaneamente e agitou-se os recipientes.

A teoria para cinética química diz que quanto maior a área de contato, maior será a velocidade da reação. Dessa forma, os alunos visualizaram que a reação com a batata ralada aconteceu mais rapidamente que a reação do recipiente que continha batata em pedaço e em tiras devido a área de contato da batata ralada ser maior em relação aos outros cortes.

\section{d) Efeito do catalizador.}

Adicionou-se $5 \mathrm{ml}$ de água oxigenada comercial vol. 10 nos três recipientes plásticos, já umedecidos com detergente. Colocou-se os recipientes plásticos um ao lado do outro, adicionou-se 2 gotas da solução de iodeto no primeiro recipiente e agitou-se, no segundo recipiente adicionou-se alguns pedacinhos de batatinha e agitou-se, no terceiro recipiente não foi adicionado nada.

O catalizador é uma substancia capaz de acelerar a velocidade da reação, porém não é transformada durante a reação podendo ser recuperado ao final da reação química.

Neste experimento com diferentes catalisadores (batata e solução de iodeto de potássio) e sem catalisador, verificou-se que a maior velocidade de reação ocorreu no recipiente que continha a solução de iodeto de potássio.

No recipiente onde a batata era o catalizador a reação ocorreu um pouco mais lenta que a reação catalisada pelo iodeto de potássio, porém muito mais rápida que a reação sem catalizador mostrando a força de cada catalizador. As equações abaixo representam as reações que ocorreram nesse experimento. Equação 2, reação não catalisada, equação 3, reação catalisada pela batata e equação 4, reação catalisada pela solução de iodeto de potássio.

$$
\begin{array}{cc}
\mathrm{H}_{2} \mathrm{O}_{2} \rightarrow \mathrm{H}_{2} \mathrm{O}+1 / 2 \mathrm{O}_{2} & \text { equação 2 } \\
\mathrm{H}_{2} \mathrm{O}_{2}+\text { batata } \rightarrow \mathrm{H}_{2} \mathrm{O}+1 / 2 \mathrm{O}_{2}+\text { batata } & \text { equação 3 } \\
\mathrm{H}_{2} \mathrm{O}_{2}+\mathrm{KI} \rightarrow \mathrm{KI}+\mathrm{H}_{2} \mathrm{O}+1 / 2 \mathrm{O}_{2} & \text { equação 4 }
\end{array}
$$




\subsection{2- ELETROQUÍMICA}

\section{a) Pilha de batatas.}

Três fios de cobre encapados e com extremidade desencapadas foram usados da seguinte forma: Uma das pontas do primeiro fio de cobre foi fixada em um prego e a outra ponta em uma moeda de cobre. Um segundo fio de cobre foi ligado ao polo positivo de uma calculadora em uma das pontas, enquanto a outra ponta foi fixada em uma moeda. O terceiro fio de cobre foi ligado ao polo negativo da calculadora e a outa extremidade a prego.

Uma batata cortada ao meio foi utilizada como eletrólito. Nas duas metades da batata foi fixado o primeiro fio de cobre sendo que a moeda de cobre ficou em uma metade e o prego em outra. Na metade da batata que havia o prego foi fixado a extremidade do segundo fio de cobre que continha a moeda. A extremidade do terceiro fio de cobre contendo o prego foi fixado na metade da batata que continha a moeda. Sendo que em cada metade da batata foram fixados um prego e uma moeda conforme a Figura 1. Os pregos e as moedas foram fixados a profundidade de $1,5 \mathrm{~cm}$ aproximadamente.

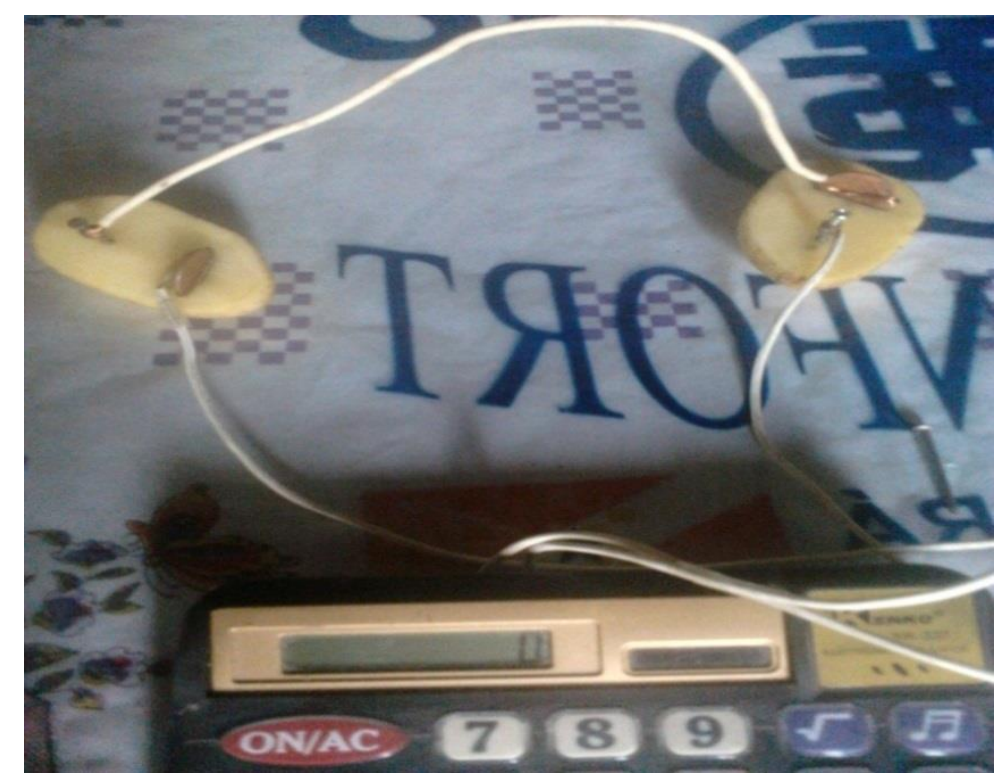

Figura 1: Calculadora ligada por meio de uma pilha de batata.

Fonte: Autores do trabalho

Neste experimento foi possível ligar a calculadora com a energia gerada pela pilha de batata. A energia foi gerada pelo fluxo de elétrons devido a diferença de potencial (ddp) dos eletrodos (conjunto formado em cada metade da batata).

Todo metal tem a capacidade de ser reduzido (receber elétrons) ou oxidado (perder elétrons). O potencial padrão de redução do cobre representado pela moeda de cobre é $+0,34$ Volt, maior que a do zinco representado pelo prego que é de $-0,76$ Volt. Como o cobre possui o maior potencial padrão de redução ele estará no catodo da pilha, ou seja, será reduzido, e o zinco será oxidado pois possui o menor potencial padrão de redução, estará no anodo da pilha. O potencial total da pilha será $+1,10$ volt conforme a equação 5 , está voltagem foi capaz de ligar a calculadora.

A batata funciona como ponte salina, pois possuem eletrólitos (sais de sódio e potássio) e garante o equilíbrio iônico da pilha. O fio de cobre age como contato elétrico por onde os elétrons são transferidos do zinco para o cobre. Dessa forma a ddp gerada nessa pilha foi capaz de ligar a calculadora.

$$
\mathrm{E}_{\text {Pilha }}^{\mathrm{o}}=\mathrm{E}_{\text {(catodo) }}^{\mathrm{o}}-\mathrm{E}_{\text {(anodo) }}^{\mathrm{o}} \text { equação } 5
$$




\section{b) Corrente elétrica em solução.}

Primeiramente isolamos os fios de um plug com fita isolante onde ficará a lâmpada, para conectar na tomada, a outra parte do fio foi colocado no copo contendo água, mantendo as pontas dos fios separadas. Conectou-se o plug na tomada e com auxílio de uma colher adicionou-se aos poucos sal de cozinha dentro do copo com água. Como mostrado na Figura 2.

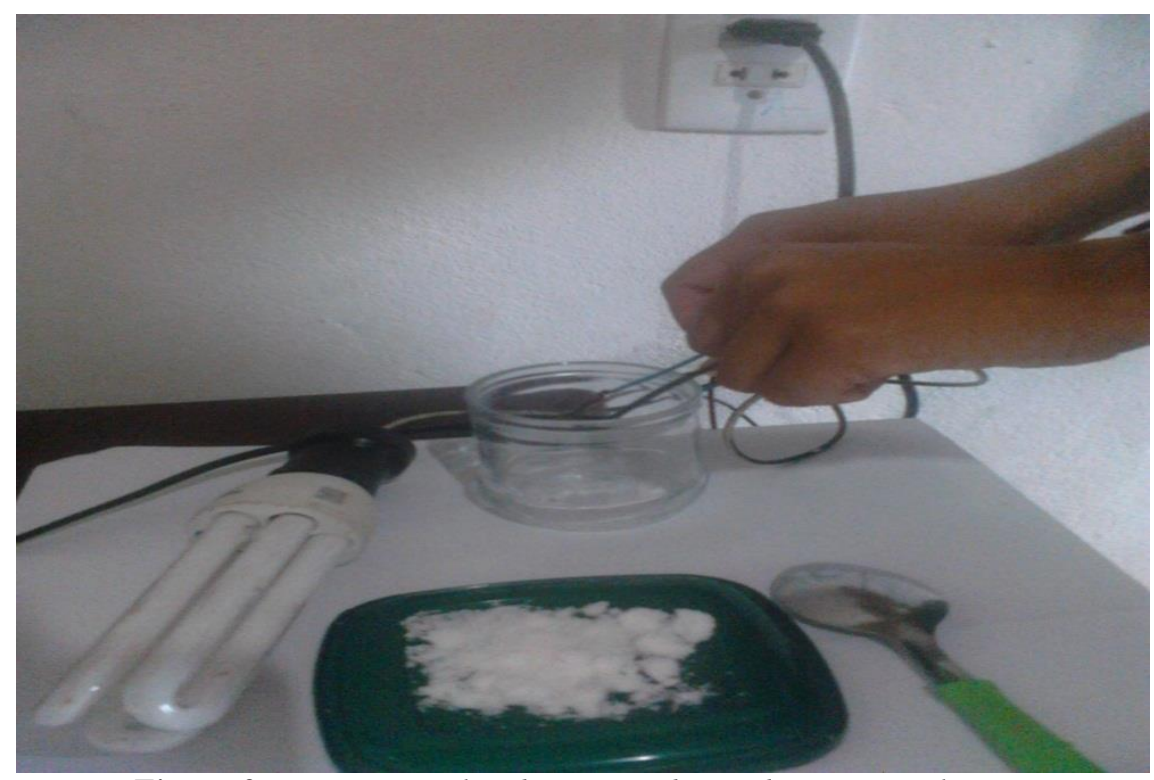

Figura 2: Materiais utilizados na condução de corrente elétrica.

Fonte: Autores do trabalho

A lâmpada acende, pois há uma passagem de corrente elétrica de uma ponta a outra dos fios. E para que isso aconteça é necessário que haja movimentação de elétrons. Quando a substância iônica (sal de cozinha, $\mathrm{NaCl}$ ) é adicionada a água. $\mathrm{O}$ sal, que foi utilizado, é uma substância que ao ser adicionado á água sofre um processo de dissociação, isto é, os íons se separam em $\mathrm{Na}^{+} \mathrm{e}$ $\mathrm{Cl}^{-}$. Esses íons ficam livres para se movimentar. É justamente essa movimentação que permite a condução de corrente elétrica fechando o circuito e acendendo a lâmpada.

\section{c) Visualização do fenômeno de oxirredução.}

O experimento inicia-se com $40 \mathrm{ml}$ de água sanitária em um recipiente plástico e adição de um pequeno pedaço da esponja de aço. Após 20 minutos foi retirada a esponja com uma pinça.

Neste experimento (Figura 3) observou-se a formação de ferrugem depositada no fundo do recipiente, devido a ação de oxirredução entre o ferro da palha de aço e a solução de hipoclorito de sódio, que é representado pela equação 6 .

$$
2 \mathrm{Fe}_{(\mathrm{s})}+3 \mathrm{NaClO}_{(\mathrm{aq})} \rightarrow \mathrm{Fe}_{2} \mathrm{O}_{3(\mathrm{~s})}+3 \mathrm{NaCl}_{(\mathrm{aq})} \quad \text { equação } 6
$$




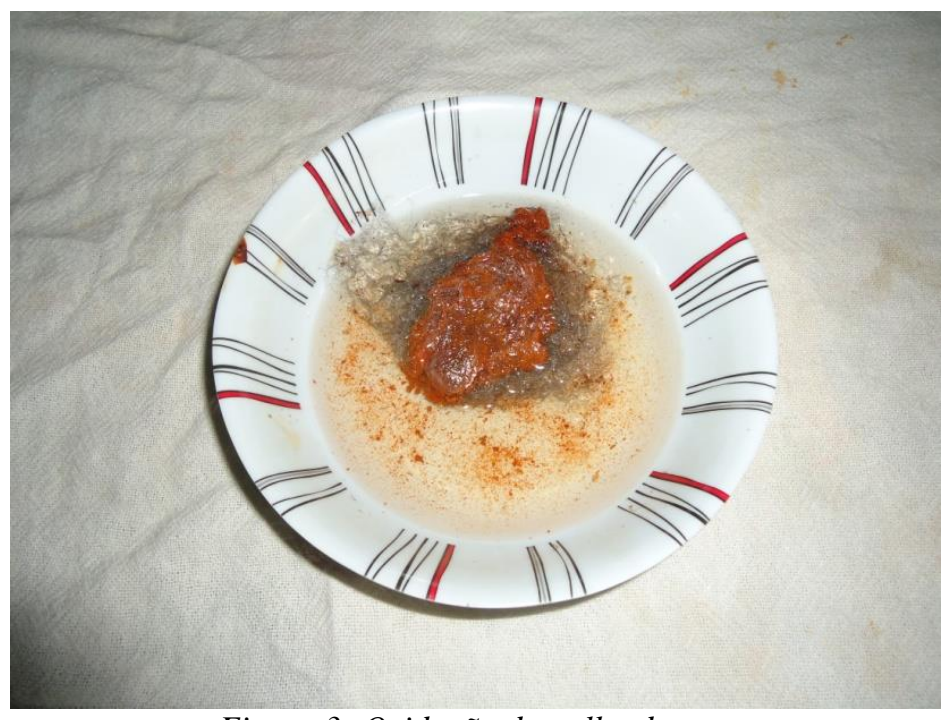

Figura 3- Oxidação da palha de aço

Fonte: Autores do trabalho

\section{RESULTADO E DISCUSSÕES}

Foram aplicados questionários pedagógicos sobre os temas de cinética química e eletroquímica. Baseado nas respostas dos alunos da E.E.E.M. Dr. Gaspar Viana, Marabá-PA, foi possível avaliar estatisticamente o interesse dos alunos pela disciplina química, o nível de aprendizado, conhecimento adquiridos sobre os temas anteriormente mencionados além da importância de aulas experimentais no ensino médio.

Sobre o questionário pedagógico, quando perguntamos qual sua opinião sobre os assuntos de química ministrados em sala de aula, 45,0 \% do total de 129 alunos responderam "Razoável, mas poderia ser melhor" e apenas $12,0 \%$ responderam "Ótimo, muito interessante", porém após a realização dos experimentos de baixo custo em sala de aula, esses valores percentuais passaram de $45 \%$ para $10 \%$ sobre a resposta Razoável e de $12 \%$ para $61 \%$ sobre a resposta Ótimo, ou seja, houve um aumento significativo no interesse dos alunos pela disciplina química depois das atividades experimentais que ajudaram a elucidar questões teóricas sobre os temas abordados.

Os resultados estatísticos sobre o questionário pedagógico indicaram ainda que a atenção dos alunos em sala de aula após a realização dos experimentos aumentou em torno de $25 \% \mathrm{em}$ relação ao ensino tradicional. O que nos leva a crer que aulas experimentais sobre assuntos de química estimularam os alunos de ensino médio da rede pública, contribuindo para que estes adquiram a curiosidade científica sobre química, e porque não sobre ciências de forma geral.

A importância de aulas experimentais de química pode ser avaliada estatisticamente na Figura 4, onde, observa-se a aceitação e necessidades de aulas experimentais, indicadas por alunos e professores da rede pública de ensino. Nesta Figura, 78\% entre alunos e professores do ensino médio disseram que aulas experimentais seriam de grande contribuição para $o$ aprendizado, principalmente sobre temas "complexos" que a química trabalha. 


\section{AULAS DE QUÍMICAS MAIS INTERESSANTES}

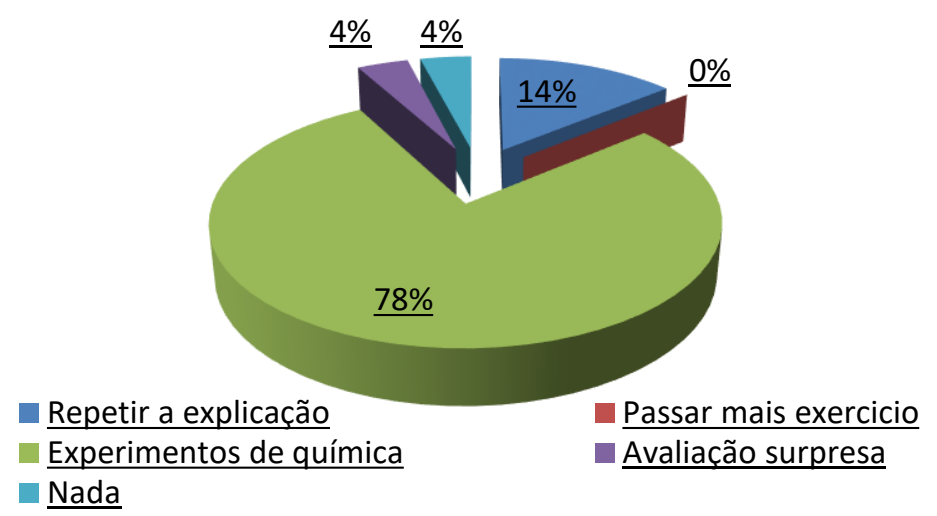

Figura 4: Análise dos questionamentos pedagógicos; O que poderia ser feito para melhorar o aprendizado de química?

Na Figura 5 é apresentado o estudo estatístico baseado nos questionários aplicados aos alunos do segundo e terceiro ano de uma escola pública da cidade de Marabá-PA

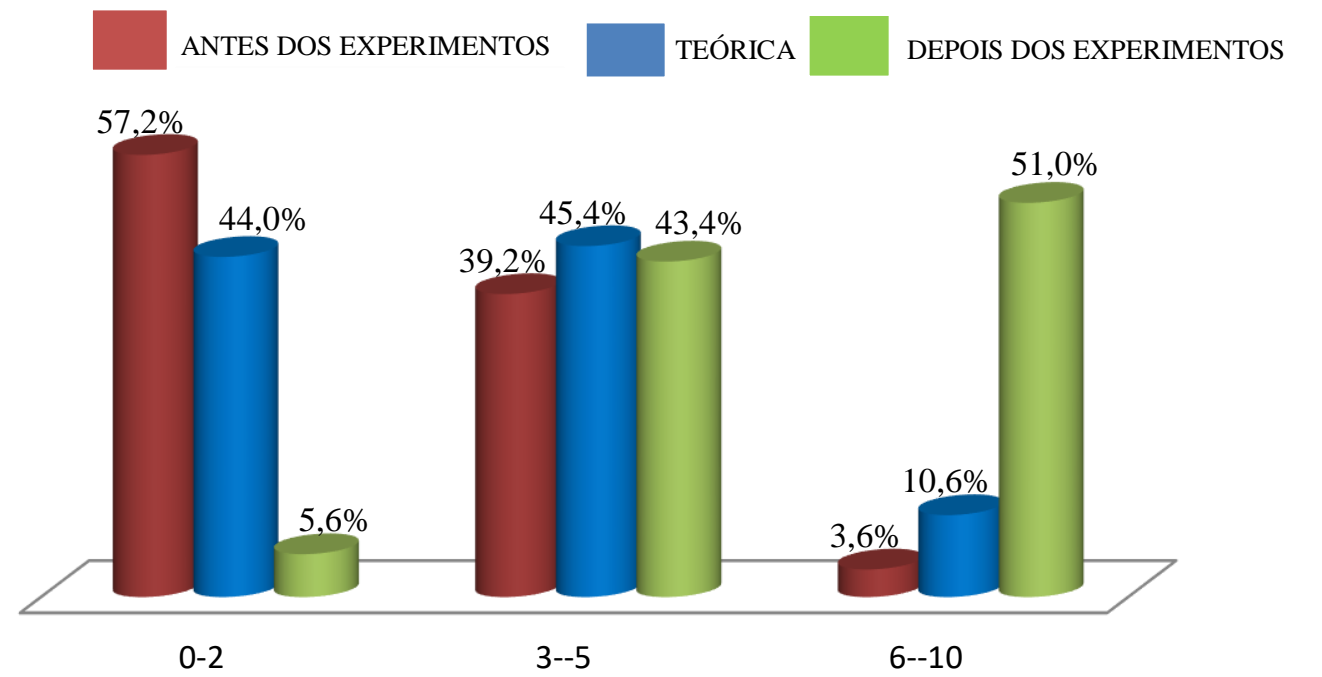

Figura 5: Análise percentual do aprendizado dos alunos antes e depois dos experimentos.

O gráfico da Figura 5 foi dividido em três faixas de notas, ou seja, pontuação alcançada pelos alunos do segundo e terceiro ano do ensino médio da rede pública após responderem aos questionários elaborados sobre os temas desenvolvidos (cinética química e eletroquímica). Sendo elas: 0 a 2 pontos, 3 a 5 pontos e 5 a 10 pontos. Onde as colunas vermelhas referem-se às respostas dos questionários antes das aulas teóricas e das aulas experimentais, as colunas azuis referem-se aos alunos que responderam os questionários depois de participarem apenas das aulas teóricas e as colunas verdes são referentes aos alunos que responderam os questionários após as aulas experimentais, ressalta-se que a teoria foi aplicada em cada experimento realizado.

Na primeira faixa de notas ( 0 a 2 pontos) podemos observar que os alunos que participaram apenas das aulas teóricas obtiveram percentual de erro alto (44\%) em relação aos alunos que participaram das aulas experimentais obtiveram menor índice de erro nesta faixa de notas $(5,6 \%)$, ou seja mesmo aqueles que assistiram as aulas teórica não souberam ou não absorveram suficientemente o conteúdo e obtiveram notas igual e/ou inferior a 2. 
Na segunda faixa de notas ( 3 a 5 pontos) não houve diferença estatística significativa. Essa faixa de notas é uma faixa intermediária e não aprovaria o aluno na disciplina, pois na escola onde o trabalho foi realizado a média para que o aluno seja aprovado é 6 .

Já na terceira faixa ( 6 a 10 pontos) as maiores notas foram alcançadas pelos alunos que participaram dos experimentos sobre cinética química e eletroquímica (51\%) e sendo este percentual muito maior em relação aos alunos que obtiveram notas entre 6 e 10 pontos apenas pelo método tradicional 10,6\% (aulas teóricas)

Em um aspecto mais restrito referente ao conteúdo de cinética química e eletroquímica. Observou-se que os alunos que realizaram os experimentos sobre os temas ministrados na sala de aula, obtiveram melhor nota em relação àqueles que tiveram apenas aulas teóricas (método tradicional). Sendo que o índice foi cerca de cinco vezes maior em relação aos alunos que não participaram das aulas experimentais, demostrando assim, que os experimentos químicos com materiais alternativos são de suma importância para que a nota dos alunos aumentasse, ou seja, aulas experimentais de química são uma ferramenta eficiente e valiosa na compreensão dos conceitos químicos.

Ressalta-se que todos os experimentos foram realizados em sala de aula com materiais alternativos e de baixo custo como forma que levar os experimentos químicos até escolas de baixa renda, e melhorar a compreensão dos conceitos químicos sem necessariamente gastar muito com laboratórios, equipamentos caros entre outro, lembrando que infelizmente a maioria das escolas públicas não possuem recurso para tanto.

Em adição a média das turmas do $2^{\circ}$ e $3^{\circ}$ ano do ensino médio que tiveram aulas experimentais foi maior, em relação às da turma que não realizaram os experimentos. Na Tabela 3 são mostradas as médias das turmas que realizaram os experimentos em sala de aula e que não realizaram.

Tabela 3- Análises estatísticas sobre as notas dos alunos com e sem experimentos.

\begin{tabular}{ll}
\hline Media entre turmas & \\
\hline Com experimentos & $7,0 \pm 1$ \\
Sem experimentos & $3,5 \pm 1$ \\
\hline
\end{tabular}

Fonte: autores do trabalho

\section{CONCLUSÃO}

Considerando-se a carência de aulas experimentais no que diz respeito ao ensino de química e as dificuldades encontradas nesse aspecto, nós bolsistas PAPIM (Programa de Apoio a Projetos de Intervenção Metodológica) concluímos que ainda é possível que professores ministrem aulas dinâmicas que auxiliem no processo ensino-aprendizagem mesmo sem dispor de grandes recursos financeiros.

A utilização de materiais alternativos para aula de ensino de química é uma proposta que tem facilitado à assimilação dos conhecimentos, além de mostrar aos professores e demais agentes da educação que mesmo com poucos recursos financeiros é possível trazer o aluno para as aulas experimentais, necessitando apenas explorar de forma mais abrangente os diversos recursos alternativos disponíveis para tornar as aulas mais atraentes.

As atividades realizaram-se em poucos minutos conforme ao tempo de duração de uma aula de Química, que tem a duração mínima de 45 minutos. Assim os resultados apresentados foram satisfatórios, comprovando que uma aula mais dinâmica, com experimentos, contribui para o binômio ensino-aprendizagem em escolas de ensino médio da rede pública.

A preparação e aplicação dos experimentos promoveram discussões sobre a importância da experimentação no ensino de química e das metodologias de ensino-aprendizagem utilizadas em sala de aula para explanar os determinados conteúdos. A utilização da dinâmica contribui com construção do saber científico a partir do conhecimento empírico dos alunos. Ademais motivaram também o professor a buscar meios de aperfeiçoar o ensino-aprendizagem para os alunos. 


\section{AGRADECIMENTOS}

Os autores agradecem ao Programa de Apoio a Projetos de Intervenção metodologia- PAPIM da Universidade Federal do Pará, pelas bolsas concedidas; Á direção e professores de Química da E.E.M Dr. Gaspar Viana e aos órgãos de fomento.

\section{BIBLIOGRAFIA}

1. Nanni R. A natureza do conhecimento científico e a experimentação no ensino de ciência. Revista Eletrônica de Ciências. 2004 v. 26.

2. Valadares EC. Propostas de experimentos de baixo custo centradas no aluno e na comunidade. Quím. Nova na Esc. 2001 13: 38-40.

3. Carvalho AM P, Gil-Pérez D. Formação de professores de ciências. 2a ed, São Paulo: Cortez; 1995. $69 \mathrm{p}$.

4. WERTHEIN, J. O ensino de ciências e a qualidade da educação. Ciência Hoje, Jornal de Ciência, Tecnologia e Empreendedorismo. Disponível em: http://www.cienciahoje.pt/. Acessado em: 20 fev. 2016.

5. Lima JFL. Contextualização no ensino de cinética química. Quím. Nova na Esc. 2000(11): 26-9.

6. Brasil. Ministério da Educação - Secretaria de Educação Média e Tecnológica. Disponível em: $<$ http://www.mec.gov.br/pcn. Acessado em12 dez. 2015.

7. Assumpcao, MHMT, Freitas, KHG, Fatibello-Filho, O. Construction and adaptation of alternative materials in acid-base titration. Eclét. Quím. 2011 35: 133 - 138, doi.org/10.1590/S010046702010000400017

8. Arroio, A. O show da química: motivando o interesse científico. Quím. Nova. 2006 29(1):173-178,

9. Feltre R. Química Geral. 4 ed. v.2. São Paulo: Editora Moderna: 1996.329-338 p.

10. Klinger M A, Barriccatti R. Práticas Pedagógicas em Cinética Química. Dia a Dia Educação, 2007 $17 \mathrm{p}$. 